\title{
UAV PLATFORMS FOR CULTURAL HERITAGE SURVEY: FIRST RESULTS
}

\author{
M. Lo Brutto ${ }^{\text {a, }}$, A. Garraffa ${ }^{\text {a }}$ P. Meli ${ }^{\text {a }}$ \\ ${ }^{a}$ Dept. of Civil, Environmental, Aerospace and Materials Engineering (DICAM), University of Palermo, Italy \\ (mauro.lobrutto, alessandra.garraffa, paola.meli)@unipa.it
}

KEY WORDS: UAVs, Cultural Heritage, Photogrammetry, Computer Vision, DSM, Ortho-image

\begin{abstract}
:
The use of Unmanned Aerial Vehicle (UAV) is becoming very common for photogrammetric survey especially due to numerous advantages compared to "traditional" aerial photogrammetry. The work carried out describes the first results obtained using different UAV systems for Cultural Heritage surveys. The study was performed acquiring two different datasets on an archaeological site and a "land art" site respectively. These datasets have different characteristics in relation to the extension of the surveyed areas, the used platform, the flight parameters. A Computer Vision approach has been used to produce 3D models and ortho-images with a very high level of detail. Some tests were also carried out to evaluate the metric accuracy of the images orientations and 3D models.
\end{abstract}

\section{INTRODUCTION}

The Cultural Heritage survey, like archaeological sites or historic centers, that have an area of some square kilometer, has always been quite problematic for the absence of appropriate tools that allow to bridge the gap between the "traditional" aerial photogrammetry and terrestrial surveying (topographic, photogrammetric or laser scanner). Recently this gap has been bridged by the development and the spread of small unmanned aerial platforms (micro and mini UAVs or Unmanned Aerial Vehicles, also known as "drones"); the UAVs fly in a range between 20 and 200 meters and allow both the acquisition of metric and qualitative data with high level of detail (Eisenbeiss \& Sauerbier, 2011). The UAVs, principally developed for military applications, are becoming very useful and very common in many civil applications; their diffusion is mainly due to the possibility to obtain images of the interest area with many advantages such as rapidity of the aerial survey, low cost of the acquisition phases, ability to map inaccessible areas and to obtain image ground resolution greater than that obtainable from "traditional" aerial photogrammetry.

The UAVs can fly autonomously or via remote control and they are able to upload a wide range of sensors such as digital cameras, thermocameras or, in some cases, also laser scanner systems. The existing platforms are classified according to the weight, the engine characteristics, the payload, the maximum distance of flight, the flight altitude, the type of wing (fixed or rotating). The UVS-International classifies the UAVs into three major classes: tactical, strategic and for special purposes (Remondino et al., 2011). The UAVs used for photogrammetric scope usually belong to the tactical UAVs; in particular, they belong to the mini and micro UAVs sub categories.

Recently the UAVs have become popular especially in the field of architectural and archaeological survey (Pueschel et. al, 2008; Chiabrando et al., 2011; Seitz \& Altenbach, 2011; Lo Brutto et al. 2012). In this area the main applications consist in the production of 3D point clouds or digital terrain models (DTM or DSM) and ortho-images with great accuracy and high spatial resolution.
The processing workflow generally is subdivided into different steps: flight planning, images acquisition, images orientation and 3D point cloud and ortho-images production. Each step shows problems that could depend on various factors. Flight planning is influenced by characteristics of the platform like the payload, that determines the choice of the sensor to use, and the flight autonomy, that defines the extent of survey area. The acquisition phase is influenced by the site morphology, by the presence of risks for the flight (obstacles, proximity of congested or urban areas) and by weather conditions (wind during the flight). The images processing is strongly affected by the irregularities of photogrammetric blocks and by the high number of images (often more of 100) necessary to completely cover the study areas.

Several experiments were carried out for the latter aspect, comparing software arising from photogrammetry and from Computer Vision (CV) (Irschara et al., 2010; Neitzel \& Klonowski 2011; Verhoeven et al., 2011; Haala \& Rothermel, 2012; Lo Brutto et al., 2012; Rosnell \& Honkavaara, 2012; Mancini et al., 2013; Sona et al., 2013), but few examples were reported concerning the quality of metric accuracy in relation to the use of CV techniques and, in particular, to the use of Structure from Motion (SfM) approach against different image network configurations (Nocerino et al., 2013). At present it is unclear if the use of more stable block configuration could improve the accuracy and the reliability of results for UAV images processed by $\mathrm{CV}$ approach.

The activities carried out in the present work aims to make a first assessment on the UAV platforms potential in Cultural Heritage survey through the analysis of several datasets that differ for the type of UAV, the flight characteristics and the extension of the area. The paper reports also some tests for the evaluation of the accuracy of images orientations and 3D point cloud production. The image orientation accuracy was evaluated taking into account different photogrammetric block geometries. The $3 \mathrm{D}$ point clouds were analyzed using some check points measured by a GNSS RTK survey.

The tests have been conducted on a small area inside the Valley of the Temples in Agrigento (Sicily, southern Italy) and in a

\footnotetext{
* Corresponding author.
} 
large area relative to the "Cretto of Gibellina" near Trapani (Sicily, southern Italy).

The Valley of the Temples dataset was acquired with a microdrone md4-200 quadricopter, while the "Cretto of Gibellina" dataset was carried out with a Sensefly Swinglet CAM fixed-wing platform. The two platforms are different in flight duration, flight altitude and acquisition mode. The microdrone md4-200, like all multi-rotor, has less wind resistance and can fly at very low altitudes (10 - 20 meters); moreover, it has a greater flexibility during the acquisition phase and allows to perform both nadiral and oblique images. The Sensefly Swinglet CAM, instead, has greater wind resistance and flies at altitudes above 100 meters (typically 140160 meters); it allows to take only nadiral images according to the classical scheme of aerial photogrammetry. Though the two platforms belong to the same UAV category and have similar field of application, the systems produce different products: very large scale surveys (pixel 1 or $2 \mathrm{~cm}$ ) of limited areas for the quadricopter, large scale surveys (pixel about $5 \mathrm{~cm}$ ) of areas of some square kilometer for fixed-wing platform. For this reason, the two platforms may be regarded as integrated tools in the low altitude survey; both platforms could be used on a same area to obtain a general large scale survey (with fixed-wing platform) and a very high level of detail survey for limited sectors (with quadricopter platform).

\section{DATA ACQUISITION}

\subsection{The aerial platforms}

The aerial photogrammetric survey of the two areas was realized with two UAV systems with different performance and characteristics (Table 1)

\begin{tabular}{|l|c|c|}
\hline & md4-200 & Swinglet CAM \\
\hline Weight (gr.) & 900 & 500 \\
\hline Diameter (cm) & 70 & 80 \\
\hline Payload (gr.) & 200 & 150 \\
\hline Operation range (m) & 500 & 2000 \\
\hline Maximum relative height (m) & $20-150$ & $120-200$ \\
\hline Flight time (min.) & 20 & 30 \\
\hline Engine & 4 electric brushless & 1 electric brushless \\
\hline Camera & Pentax Optio RZ18 & Canon IXUS 125 HS \\
\hline GPS & YES & YES \\
\hline Auto-pilot & YES & YES \\
\hline Wind resistance (m/s) & 4 & 7 \\
\hline
\end{tabular}

Table 1. UAVs characteristics

The first vehicle is a microdrone md4-200 remotely piloted quadricopter with carbon fiber body, total weight of 900 grams and a diameter of less than 1 meter (Figure 1). This drone belongs to the class VTOL-aircraft (Vertical Take-Off and Landing) and is equipped with different sensors (accelerometer, gyroscope, magnetometer, barometer, GPS) that allow to execute automated flights and to provide more stability. The vehicle is equipped with four independent brushless electric motors and can carry up to 200 gr instruments with flight duration capability of 20 minutes and wind resistance of $4 \mathrm{~m} / \mathrm{s}$. The platform is managed by the software mdCockpit that provides information about the aircraft status, the battery level, position, altitude, number of satellites available for GNSS positioning, speed and flight time. The sensors used for aerial acquisitions are mounted on a carbon fiber structure that allows rotation of $100^{\circ}$ relative to the horizontal and therefore offers the opportunity to acquire both nadiral and oblique images.

The second vehicle is the fixed-wing drone Swinglet CAM developed by Sensefly with a very light body, only 500 grams, made of expanded polystyrene with rear-mounted propeller and a wingspan of $80 \mathrm{~cm}$ (Figure 2). This carrier usually flies at a height of around 100-120 meters and is able to fly up to 30 minutes allowing to cover areas up to 4 square kilometers in a single flight in standard conditions. The standard equipment is composed of several types of sensors such as GPS, gyroscope, accelerometer, etc.. that make the platform extremely stable and easy to use. The take-off is carried out by hand, while the landing is performed autonomously in an area of a diameter of about $40 \mathrm{~m}$ and free of prominent obstacles. It has a wind stability higher than the quadricopter as it can fly up to a wind speed of $7 \mathrm{~m} / \mathrm{s}$. The vehicle is radio controlled from a PC through the software eMotion that lets you plan, simulate, monitor and control the trajectory of the carrier both before and during the flight. The system allows to acquire only nadiral images.

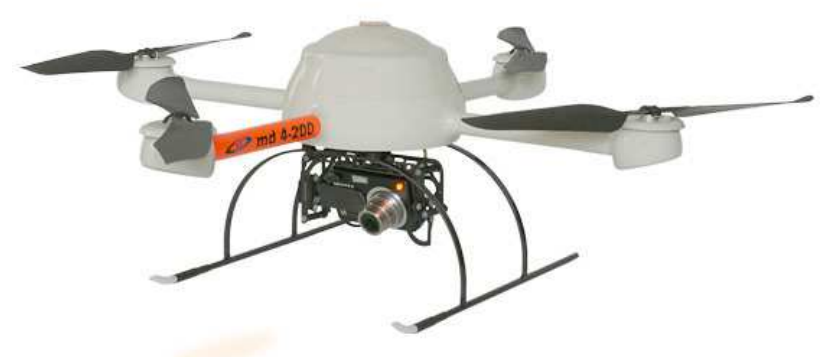

Figure 1. The microdrone md4-200

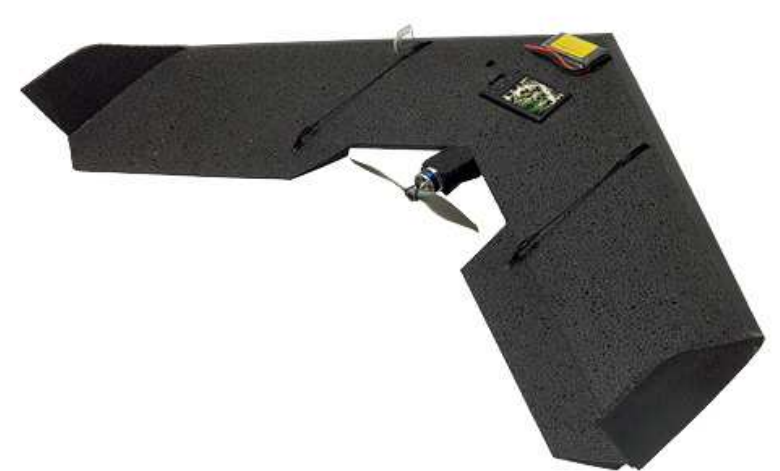

Figure 2. The Sensefly Swinglet CAM

\subsection{Study area}

The two systems were tested in two different sites: the area of the Temple of Isis in the Archaeological Park of the Valley of the Temples in Agrigento was surveyed with the microdrone md4-200, the area of the "Cretto of Gibellina" near the town of Trapani with the Swinglet CAM.

The former is one of the least known zones of the entire archaeological park and then uncrowded by tourists. The temple is situated in an area only partially excavated and is constituted by a podium and a triportico that defines a square (Figure 3 ). 
The interior of the temple contained a cell preceded by a pronaos and followed by a protruding portion on podium accessible through lateral ramps. The triportico was characterized by sixty-two columns and two half columns terminals.

The latter is a work of the artist Alberto Burri realized between 1984 and 1989 in the site where was once located the town of Gibellina, which was destroyed in 1968 due to the earthquake of the Belice Valley. This structure is one of the major example of the so-called "land art". The artist decided to cover the ruins of the town with concrete to form "islands" that reproduce the old streets of the town. The idea of the artist was to create a place of memory. The islands are separated by reinforced concrete walls about $1.6 \mathrm{~m}$ high. The "Cretto of Gibellina" covers an area of about $300 \mathrm{~m} \times 270 \mathrm{~m}$ and has a difference in height of about $100 \mathrm{~m}$ (Figure 4). The "Cretto of Gibellina" is continuously exposed to weather conditions and therefore has several degradations and cracks due to the slow creep of the substratum.

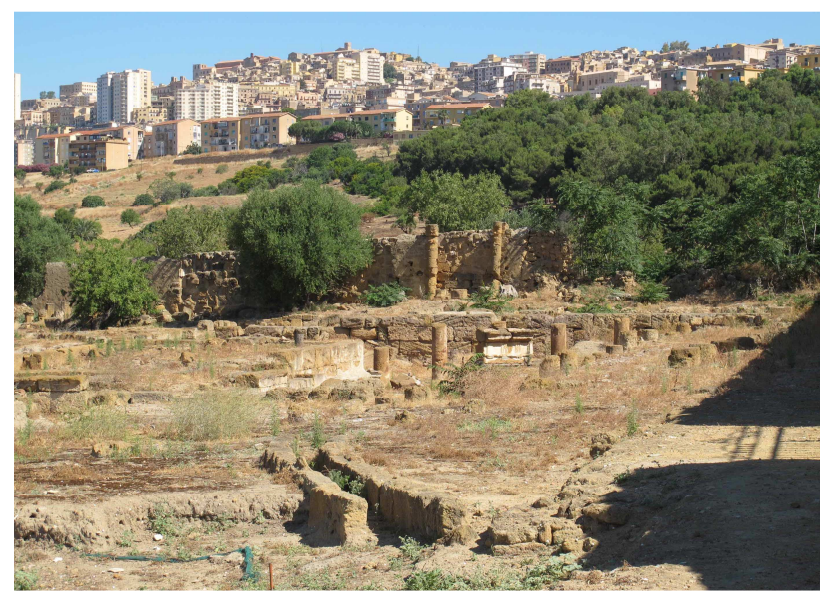

Figure 3. The Temple of Isis

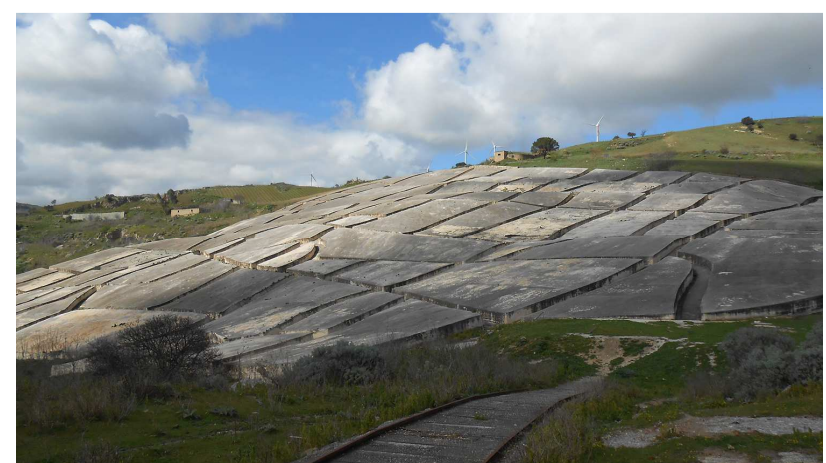

Figure 4. The "Cretto of Gibellina"

\subsection{UAV survey}

The two study areas were surveyed through the planning of two flights with strips oriented along perpendicular directions; in this way it was possible to perform different tests in relation to the geometric configurations of the flights. As reported in Nocerino et al. (2013) "network design has been a key topic in photogrammetry when accurate and reliable measurements have to be performed" but the use of fully automatic processes arising from $\mathrm{CV}$ has overshadowed this aspect.

According to the development of the areas the flight directions were approximately coincident with the North-South and EastWest direction. All flights were planned imposing a classical photogrammetric aerial scheme (nadiral images) with forward overlap of $80 \%$ for both areas and a side overlap of $70 \%$ and $80 \%$ for the area of the Temple of Isis and for the "Cretto of Gibellina" respectively.

The two platforms were equipped with two compact digital cameras. In particular the quadricopter md4-200 was provided with a 16 Megapixel Pentax Optio RZ18 with a zoom lens variable from $4.5 \mathrm{~mm}$ to $81 \mathrm{~mm}$, while the Swinglet CAM was equipped with a 16 Megapixel Canon IXUS 125 HS with zoom lens variable from $4.3 \mathrm{~mm}$ to $21.5 \mathrm{~mm}$. Both cameras were set to wide mode (minimum focus distance) and focus to infinity.

All flights were performed in automatic mode according to the flight plan.

The flights of the area of the Temple of Isis covered an area of about 0.57 ha; the flight North-South had a relative height of about $71 \mathrm{~m}$, while East-West of about $65 \mathrm{~m}$. According to these parameters the Ground Sample Distance (GSD) was about 1.9 $\mathrm{cm} /$ pix and about $1.6 \mathrm{~cm} /$ pix respectively. For each waypoint two images were acquired to obtain a minimum data redundancy.

For the survey of the "Cretto of Gibellina" two flights were also performed (North-South and East-West) with a relative height of about $160 \mathrm{~m}$ allowing to get a GSD of about $5 \mathrm{~cm} /$ pix. The flights were performed setting one shot every 3 seconds and according to the major size of the area a large number of images was obtained. Table 2 summarizes the main flights features.

\begin{tabular}{|c|c|c|c|c|c|c|c|}
\hline Dataset & $\begin{array}{c}\text { Area } \\
\text { [ha] }\end{array}$ & $\begin{array}{c}\text { Flight } \\
\text { direction }\end{array}$ & $\begin{array}{c}\text { Forward } \\
\text { overlap }\end{array}$ & $\begin{array}{c}\text { Side } \\
\text { overlap }\end{array}$ & $\begin{array}{c}\text { Relative } \\
\text { height } \\
\text { [m] }\end{array}$ & $\begin{array}{c}\text { Number } \\
\text { of } \\
\text { images }\end{array}$ & $\begin{array}{c}\text { GSD } \\
\text { [cm/pix] }\end{array}$ \\
\hline $\begin{array}{c}\text { Temple of } \\
\text { Isis }\end{array}$ & \multirow{2}{*}{0.57} & $\mathrm{~N}-\mathrm{S}$ & $80 \%$ & $70 \%$ & 71 & 24 & 1.9 \\
\cline { 3 - 8 } & $\mathrm{E}-\mathrm{W}$ & $80 \%$ & $70 \%$ & 65 & 27 & 1.6 \\
\hline \multirow{2}{*}{$\begin{array}{c}\text { "Cretto of } \\
\text { Gibellina" }\end{array}$} & 30 & $\mathrm{~N}-\mathrm{S}$ & $80 \%$ & $80 \%$ & 160 & 85 & 5.0 \\
\cline { 3 - 8 } & $E-W$ & $80 \%$ & $80 \%$ & 160 & 76 & 5.0 \\
\hline
\end{tabular}

Table 2. Flight parameters

Before starting the data acquisition square targets were placed on the two sites; some of them were used as Ground Control Points (GCPs) and others as Check Points (CPs). The targets were appropriately sized according to the relative height of the flight for the two areas $(20 \mathrm{~cm} \times 20 \mathrm{~cm}$ for the area in the Archeological Park of Agrigento and $40 \mathrm{~cm} \mathrm{x} 40 \mathrm{~cm}$ for the "Cretto of Gibellina") (Figure 5).

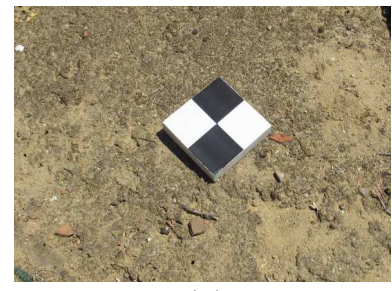

(a)

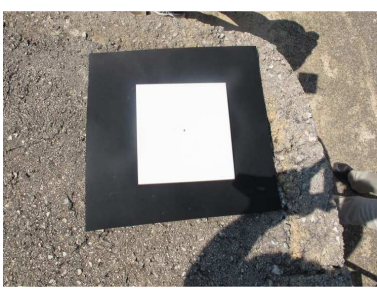

(b)
Figure 5. Targets used for the area in the Archeological Park of Agrigento $(a)$ and for the "Cretto of Gibellina" $(b)$

In UAV applications it is necessary to measure a rather high number of GCPs due to the high number of images that are normally acquired during the survey and due to the irregularity of the photogrammetric blocks. Generally techniques sufficiently rapid were used to carry out GCP measurements such as GNSS RTK (Real Time Kinematic) or GNSS NRTK (Network Real Time Kinematic).

The theoretical accuracy of these techniques is on the order of a few centimeters, but this accuracy could be even worse because 
of errors that may occur during the survey phase (operator errors, bad satellite configurations, etc...).

In this work the target coordinates were obtained by a GNSS RTK survey using a master station located within the areas of survey, without exceeding the distance of one kilometer between the master and rover. The coordinates were referenced to WGS84 UTM-ETRF2000 reference system. The precision of the topographic survey was calculated through the Root Mean Square Error (RMSE) obtained during the survey phase; this value was about $\pm 1 \div 2 \mathrm{~cm}$, as it was expected.

Furthermore, in order to estimate more precisely the accuracy of the control points coordinates, the target coordinates of the Temple of Isis were measured twice in two different days. The comparison between the coordinates of the two surveys allowed to calculate a RMSE of about $\pm 1.2 \mathrm{~cm}$ both for the planimetric and the altimetric accuracies with maximum errors especially for the elevation also on the order of $4 \mathrm{~cm}$. This test, although not statistically rigorous, gives a more realistic idea of the accuracy of the control points and of the accuracy that could be expected from the photogrammetric survey.

\section{DATA PROCESSING}

\subsection{Image orientation}

Image orientation was also conducted to carry out some first evaluations on the metric accuracy of UAV photogrammetric surveys. The flights for both study areas (Temple of Isis and "Cretto of Gibellina") were processed and evaluated separately in relation to the different UAV. Before image orientation a selection of images for each waypoint was conducted for the Temple of Isis dataset choosing the best in relation to the radiometric and geometry characteristics.

Different analysis were performed considering the following block geometry (Figures 6 and 7):

\section{- $\quad$ East-West block (EW Block)}

- North-South block (NS Block)

- East-West block including two flight strips cross block (EW Block + cross strip)

- North- South block including two flight strips cross block (NS Block + cross strip)

- Both East-West and North-South blocks (EW Block + NS Block)

The images were processed using the low-cost package PhotoScan Professional Edition. The software is produced by Agisoft and provides a sequence of automatic steps for image orientation and image matching; moreover, PhotoScan allows to extract 3D models with a very high level of detail and orthoimages using SfM and dense stereo-matching algorithms. However, it is possible to intervene in the process at any stage to improve the result. During image orientation PhotoScan estimates both internal camera parameters (principal distance, principal point location, skew, radial and tangential distortion coefficients) and external camera orientation for each image; the results of image orientation (called photo alignment in PhotoScan) is a sparse point cloud. The alignment can be performed setting some parameters; particularly, it is possible to set the "accuracy" of the process (low, medium, high), the image pair preselection (to speed up the selection of image pairs to be matched) and the maximum number of feature points on every image (by default is 40000 points). For our processing an "accuracy" high was set, the UAVs telemetries were used for image pair preselection and the default number of points per image was chosen.

In PhotoScan package it is possible to set the reference system using GCPs (called marker in PhotoScan) coordinates; the coordinates can be loaded from an external file and can be referenced to a local or to a cartographic reference system. Markers could be used also to "optimize" internal camera parameters and image orientation to compensate the non-linear model deformation that could be produce high georeferencing errors.

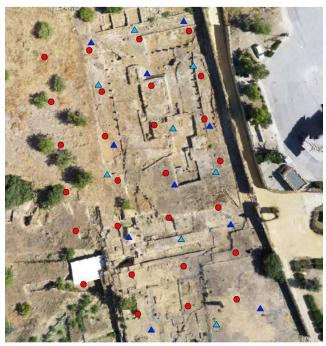

(a)

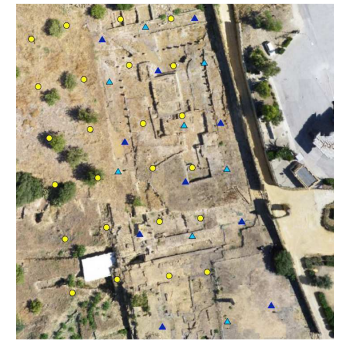

(b)

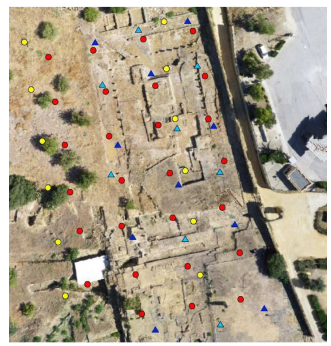

(c)

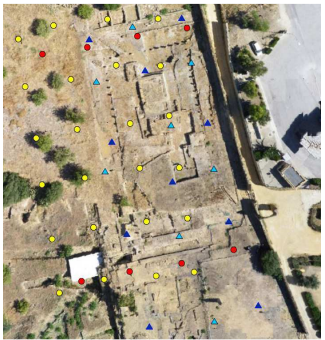

(d)

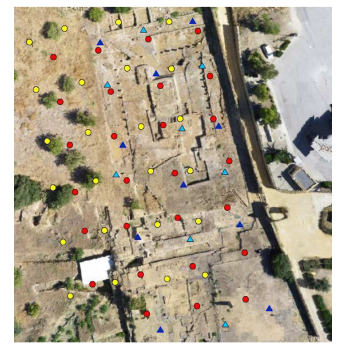

(e)

Figure 6. Different blocks configurations used for the analysis of the Temple of Isis: East-West Block $(a)$; North-South Block $(b)$; EastWest Block including two flight strips cross block (c); North- South block including two flight strips cross block (d); Both East-West and North-South Blocks (e); in blue the GCPs and in cyan the CPs.

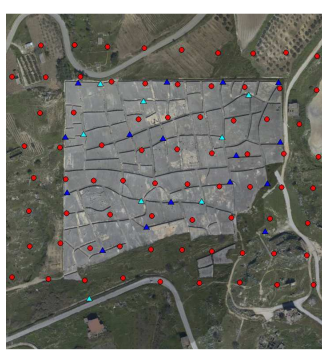

(a)

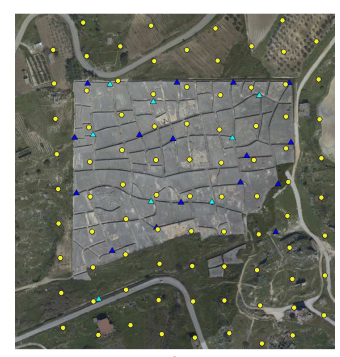

(b)

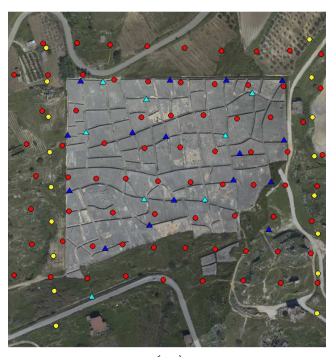

(c)

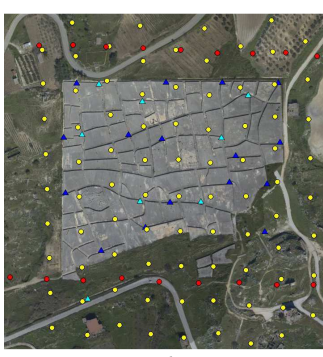

(d)

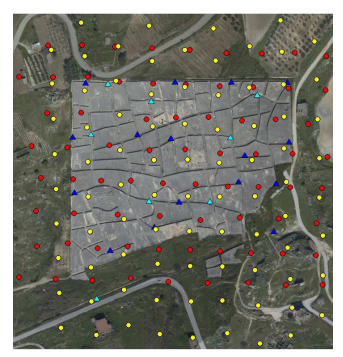

(e)

Figure 7. Different blocks configurations used for the analysis of the "Cretto of Gibellina": East-West Block $(a)$; North-South Block $(b)$; East-West Block including two flight strips cross block $(c)$; North- South block including two flight strips cross block $(d)$; Both East-West and North-South Blocks $(e)$; in blue the GCPs and in cyan the CPs. 


\begin{tabular}{|c|c|c|c|c|c|c|c|c|c|c|c|}
\hline \multirow{2}{*}{$\begin{array}{l}\text { Temple of } \\
\text { Isis }\end{array}$} & \multirow{2}{*}{$\begin{array}{l}\text { Num. of } \\
\text { Images }\end{array}$} & \multirow{2}{*}{$\begin{array}{l}\text { Num. } \\
\text { CGPs }\end{array}$} & \multirow{2}{*}{$\begin{array}{l}\text { Num. } \\
\text { CPs }\end{array}$} & \multicolumn{4}{|c|}{ GCPs } & \multicolumn{4}{|c|}{ CPs } \\
\hline & & & & $\begin{array}{c}\text { RMS X } \\
{[\mathrm{m}]}\end{array}$ & $\begin{array}{c}\text { RMS Y } \\
{[\mathrm{m}]}\end{array}$ & $\begin{array}{c}\text { RMS Z } \\
{[\mathrm{m}]}\end{array}$ & $\begin{array}{c}\text { RMSE XYZ } \\
{[\mathrm{m}]}\end{array}$ & $\begin{array}{c}\text { RMS X } \\
{[\mathrm{m}]}\end{array}$ & $\begin{array}{c}\text { RMS Y } \\
{[\mathrm{m}]}\end{array}$ & $\begin{array}{c}\text { RMS Z } \\
{[\mathrm{m}]}\end{array}$ & $\begin{array}{c}\text { RMSE XYZ } \\
{[\mathrm{m}]}\end{array}$ \\
\hline $\begin{array}{l}\text { EW } \\
\text { Block }\end{array}$ & 27 & 10 & 8 & 0.008 & 0.008 & 0.022 & 0.025 & 0.010 & 0.010 & 0.027 & 0.031 \\
\hline $\begin{array}{l}\text { EW Block + } \\
\text { Cross Strip }\end{array}$ & 39 & 10 & 8 & 0.020 & 0.014 & 0.026 & 0.036 & 0.022 & 0.011 & 0.029 & 0.038 \\
\hline $\begin{array}{c}\text { NS } \\
\text { Block }\end{array}$ & 24 & 10 & 8 & 0.012 & 0.008 & 0.014 & 0.020 & 0.015 & 0.007 & 0.020 & 0.026 \\
\hline $\begin{array}{l}\text { NS Block + } \\
\text { Cross Strip }\end{array}$ & 32 & 10 & 8 & 0.005 & 0.007 & 0.016 & 0.018 & 0.010 & 0.008 & 0.020 & 0.024 \\
\hline $\begin{array}{c}\text { EW Block + NS } \\
\text { Block }\end{array}$ & 51 & 10 & 8 & 0.004 & 0.008 & 0.025 & 0.026 & 0.010 & 0.007 & 0.034 & 0.036 \\
\hline
\end{tabular}

Table 3. The statistical parameters resulting from the images orientation for dataset of the Temple of Isis

\begin{tabular}{|c|c|c|c|c|c|c|c|c|c|c|c|}
\hline \multirow{2}{*}{$\begin{array}{l}\text { "Cretto of } \\
\text { Gibellina" }\end{array}$} & \multirow{2}{*}{$\begin{array}{l}\text { Num. of } \\
\text { Images }\end{array}$} & \multirow{2}{*}{$\begin{array}{l}\text { Num. } \\
\text { CGPs }\end{array}$} & \multirow{2}{*}{$\begin{array}{l}\text { Num. } \\
\text { CPs }\end{array}$} & \multicolumn{4}{|c|}{ GCPs } & \multicolumn{4}{|c|}{ CPs } \\
\hline & & & & $\begin{array}{l}\text { RMS X } \\
{[\mathrm{m}]}\end{array}$ & $\begin{array}{l}\text { RMS Y } \\
{[\mathrm{m}]}\end{array}$ & $\begin{array}{l}\text { RMS Z } \\
{[\mathrm{m}]}\end{array}$ & $\begin{array}{c}\text { RMSE XYZ } \\
{[\mathrm{m}]}\end{array}$ & $\begin{array}{l}\text { RMS X } \\
{[\mathrm{m}]}\end{array}$ & $\begin{array}{l}\text { RMS Y } \\
{[\mathrm{m}]}\end{array}$ & $\begin{array}{l}\text { RMS Z } \\
{[\mathrm{m}]}\end{array}$ & $\begin{array}{c}\text { RMSE XYZ } \\
{[\mathrm{m}]}\end{array}$ \\
\hline $\begin{array}{l}\text { EW } \\
\text { Block }\end{array}$ & 76 & 16 & 8 & 0.029 & 0.020 & 0.032 & 0.047 & 0.036 & 0.017 & 0.051 & 0.065 \\
\hline $\begin{array}{l}\text { EW Block + } \\
\text { Cross Strip }\end{array}$ & 93 & 16 & 8 & 0.023 & 0.022 & 0.031 & 0.044 & 0.021 & 0.024 & 0.056 & 0.065 \\
\hline $\begin{array}{l}\text { NS } \\
\text { Block }\end{array}$ & 85 & 16 & 8 & 0.016 & 0.013 & 0.020 & 0.028 & 0.021 & 0.017 & 0.029 & 0.039 \\
\hline $\begin{array}{l}\text { NS Block + } \\
\text { Cross Strip }\end{array}$ & 103 & 16 & 8 & 0.020 & 0.015 & 0.012 & 0.028 & 0.021 & 0.016 & 0.040 & 0.048 \\
\hline $\begin{array}{c}\text { EW Block + NS } \\
\text { Block }\end{array}$ & 161 & 16 & 8 & 0.018 & 0.014 & 0.025 & 0.034 & 0.023 & 0.025 & 0.022 & 0.041 \\
\hline
\end{tabular}

Table 4. The statistical parameters resulting from the images orientation for dataset of the "Cretto of Gibellina"

The coordinates of the target, obtained from the topographic survey, were used as GCP and CP. Ten GCPs and eight CPs are used for the Temple of Isis dataset, sixteen GCPs and eight CPs for the "Cretto of Gibellina". On the basis of the results of the topographic survey, the accuracy of the GCP has been set equal to one centimetre.

The results of the different image orientations, for GCPs and CPs, are shown in tables 3 and 4. All the results have been obtained after the "optimization" process. For the Temple of Isis dataset the planimetric accuracy was in the order of $\pm 1.5 \mathrm{~cm}$ while the altimetric accuracy was about $\pm 3.0 \mathrm{~cm}$; for the "Cretto of Gibellina" dataset we have obtained a planimetric accuracy in the order of $\pm 3.0 \mathrm{~cm}$ and an altimetric accuracy in the order of $\pm 5.0 \mathrm{~cm}$. As expected the residuals obtained for GCPs and CPs have more or less the same overall accuracy as the topographic survey; moreover the residuals in $\mathrm{Z}$ are always higher.

It is possible to note (Tables 3 and 4 ) that there are not evident improvements on residuals of CPs using more stable block configurations. In both datasets, the addition of cross strips in the East-West and North-South blocks does not improve the results. The RMS in $\mathrm{X}, \mathrm{Y}$ and $\mathrm{Z}$ are almost the same if not slightly worse (e.g., in the "Cretto of Gibellina" dataset the $\mathrm{Z}$ RMS in the NS Block + Cross Strip is greater than $1 \mathrm{~cm}$ respect to the same value in the NS Block). This might seem to contradict the classical aerial photogrammetry approach that considers useful cross strips to restrict and to control the deformation of the photogrammetric block. Furthermore, also the use of very redundant block (EO Block + NS Block) does not produce better results.

\subsection{Dense surface reconstruction and ortho-images generation}

The stereo matching procedures implemented in PhotoScan were used to carry out very dense point cloud models. The package allows to extract the dense point cloud with different predefined 3D reconstruction level of details (Lowest, Low, Medium, High, Ultra High); furthermore, it is possible to set the filtering algorithms to remove noisy points (Mild, Moderate, Aggressive).

In our work for both datasets dense surface reconstructions were calculated using only three block configurations: East-West Block, North-South Block and East-West + North-South Blocks together. The processes were executed using the "high" and "ultra-high" resolution options that permit to obtain a more detailed mesh; the filtering algorithms were set in "Moderate" mode.

The 3D reconstructions were very detailed with a points resolutions ranging from 2.5 to $3.5 \mathrm{~cm}$ for the Temple of Isis (Figure 8) and from $7 \mathrm{~cm}$ to $8 \mathrm{~cm}$ for the "Cretto of Gibellina" (Figure 9).

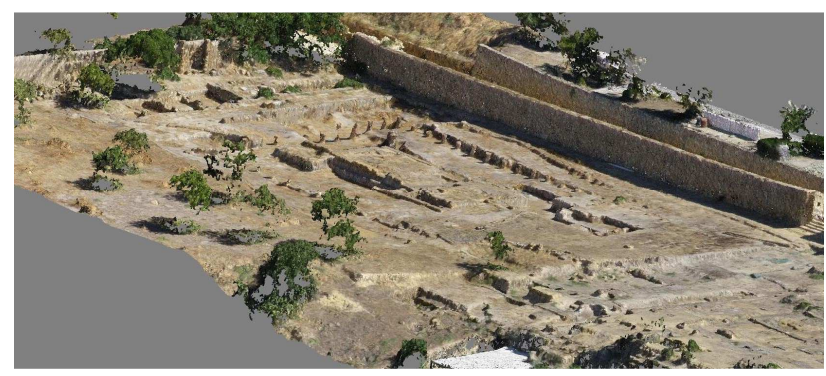

Figure 8 . 3D model of the Temple of Isis 


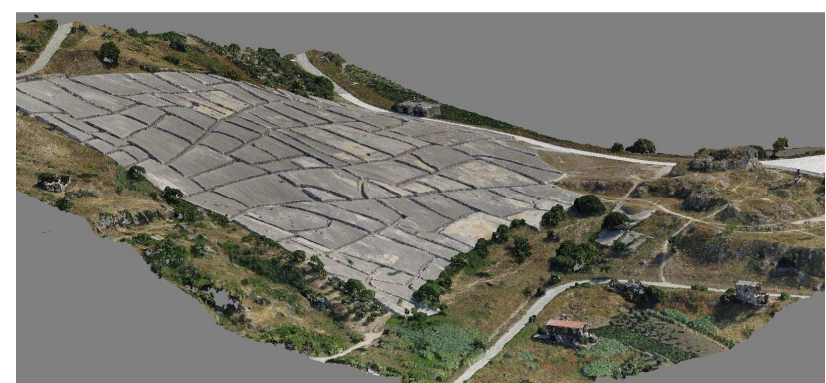

Figure 9. 3D model of the "Cretto of Gibellina"

Furthermore the ortho-images of the two areas were calculated with a geometric resolution of $2 \mathrm{~cm}$ for the Temple of Isis and 5 $\mathrm{cm}$ for the "Cretto of Gibellina". By considering the accuracy obtained, it is possible to accept a nominal scale ranging from 1:200 up to 1:100 for the ortho-images produced.

\subsection{Data comparison and results evaluation}

In order to evaluate the metric accuracy of the 3D point clouds some check points, considered as the ground truth, were measured within the two study areas using GNSS RTK techniques. Overall 376 points in the area of the Temple of Isis and 274 points in the area of the "Cretto of Gibellina" were measured. The points were distributed evenly in the areas of interest on stable and flat surfaces; in particular in the "Cretto of Gibellina" all the points were measured in the central part of the paths.

Surfer software, a grid-based mapping program that interpolates irregularly spaced XYZ data into a regularly spaced grid, was used to estimate the surface deviation between the 3D point clouds produced by PhotoScan and the GNSS RTK data. The Nearest Neighbor gridding method was used; this method is useful when data are already evenly spaced, but need to be converted to a regular grid file.

First of all, in order to perform the check, the 3D points clouds were interpolated to a regular grid with a step set in relation to their points resolution: $5 \mathrm{~cm}$ for the models of the Temple of Isis and $20 \mathrm{~cm}$ for the models of the "Cretto of Gibellina".

Afterward a quantitative analysis on vertical differences between GNSS RTK check points and the regular grids was obtained using the "Residuals" command implemented in Surfer. "Residuals" computes the vertical difference between the $\mathrm{Z}$ value in a data file and the interpolated $\mathrm{Z}$ value on a regular grid. The formula used to compute a residual value is:

$$
Z_{\text {res }}=Z_{\text {data }}-Z_{\text {grd }}
$$

where $\quad Z_{\text {res }}=$ the residual value

$Z_{\text {data }}=$ the $Z$ value of GNSS RTK data

$Z_{\text {grd }}=$ the $Z$ value of the interpolated grid surface from 3D point cloud

The statistical parameters of the comparison are shown in Table 5. In order to better evaluate the distribution of the residuals a graphic representation of the differences have been done on the ortho-images for both datasets (Figures 10 and 11).

As we can be noted from the table 5 the results obtained for the Temple of Isis dataset from the different block configurations are very similar. The RMS values range from $\pm 0.079 \mathrm{~m}$ (EW Block) to $\pm 0.086 \mathrm{~m}$ (NS Block).

Furthermore the figure 10 shows similar distributions of deviations in all considered blocks with differences more

\begin{tabular}{|c|c|c|c|c|c|}
\hline & & $\begin{array}{l}\text { Num. of } \\
\text { Points }\end{array}$ & $\begin{array}{l}\text { RMS } \\
{[\mathrm{m}]}\end{array}$ & $\begin{array}{l}\text { Minimum } \\
\text { Deviation } \\
{[\mathrm{m}]}\end{array}$ & $\begin{array}{l}\text { Maximum } \\
\text { Deviation } \\
{[\mathrm{m}]}\end{array}$ \\
\hline \multirow{3}{*}{ 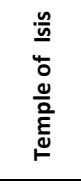 } & EW Block & 376 & 0.079 & -0.820 & 0.120 \\
\hline & NS Block & 376 & 0.086 & -0.825 & 0.106 \\
\hline & $\begin{array}{c}\text { EW Block + NS } \\
\text { Block }\end{array}$ & 376 & 0.084 & -0.838 & 0.079 \\
\hline \multirow{3}{*}{ 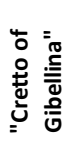 } & EW Block & 274 & 0.075 & -0.473 & 0.237 \\
\hline & NS Block & 274 & 0.050 & -0.357 & 0.217 \\
\hline & $\begin{array}{c}\text { EW Block + NS } \\
\text { Block }\end{array}$ & 274 & 0.097 & -1.080 & 0.288 \\
\hline
\end{tabular}

Table 5. Statistical parameters for the 3D point cloud evaluation

pronounced in the central part and in some areas situated in north where there are some height differences.

This homogeneity of the results for the Temple of Isis dataset is not found in the "Cretto of Gibellina" dataset. First of all the best result was obtained from the comparison with the NS Block. Indeed the RMS values range from $\pm 0.050 \mathrm{~m}$ (NS Block) to $\pm 0.097 \mathrm{~m}$ (EW + NS Block). Moreover the graphic representations show some problems (Figure 11): in the comparisons resulting from the EW Block and EW+NS Blocks there is a concentration of negative differences mainly situated in central areas, while in the comparison resulting from the NS Block the distribution of the deviations is more homogenous.

All the vertical residuals are anyway higher than those calculated on the $\mathrm{CP}$ used for the orientation phase.

It is possible to suppose that these values could be influenced by bilinear interpolation method that Surfer uses to calculate $\mathrm{Z}$ values at points that do not coincide with grid nodes, even if, considering that all the points were measured in flat areas or in areas with a constant slope, the uncertainty of the interpolation process should not be so determinant.

\section{CONCLUSION}

This paper shows the potentiality of the UAVs survey in Cultural Heritage field. Some first results can already be deduced although many aspects require further and more detailed research. Particularly, first tests related to the orientation phases do not highlight any reduction of the CPs residuals using more stable block configurations. The high redundancy of the measurements (on average each point has at least $8-10$ projections), due to the high percentage of image overlap, and the high number of tie points for every image, in the order of 2000-4000 points per image, could make unnecessary the use of photogrammetric blocks with more stable configurations.

Final products (3D models and ortho-images) show very high level of detail allowing to perform very accurate studies and analysis. Procedures followed were very quick thanks to the high level of automation achieved by the software used.

In the evaluation of $3 \mathrm{D}$ point clouds the vertical residuals obtained both for all the datasets of the Temple of Isis and for two of the three datasets of "Cretto of Gibellina" seem to be quite high. Besides the distribution of residuals shows some slight deformation in the 3D models. Further and more extensive tests are surely required to better understand the reasons for these last results. 


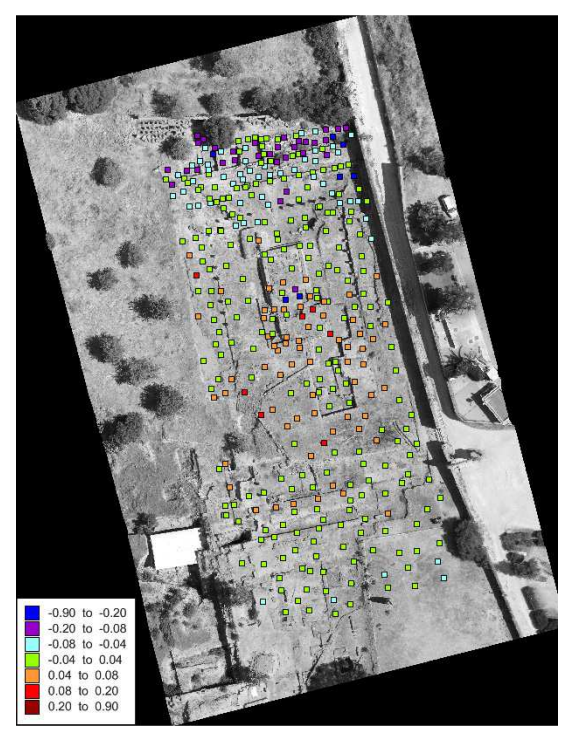

(a)

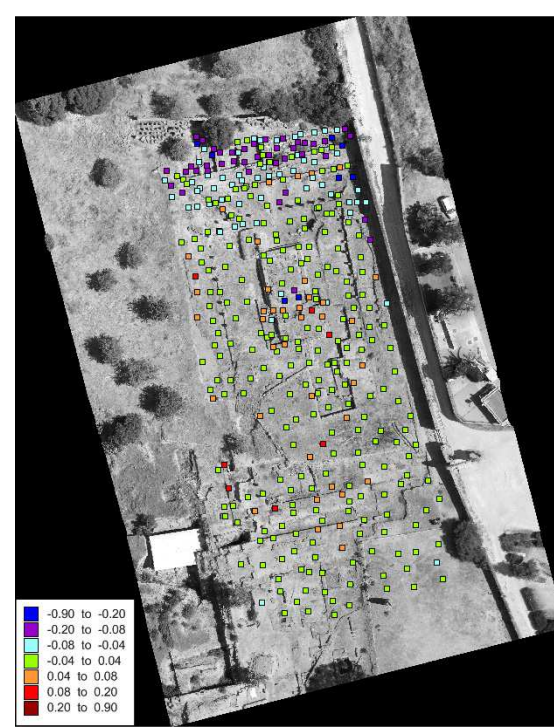

(b)

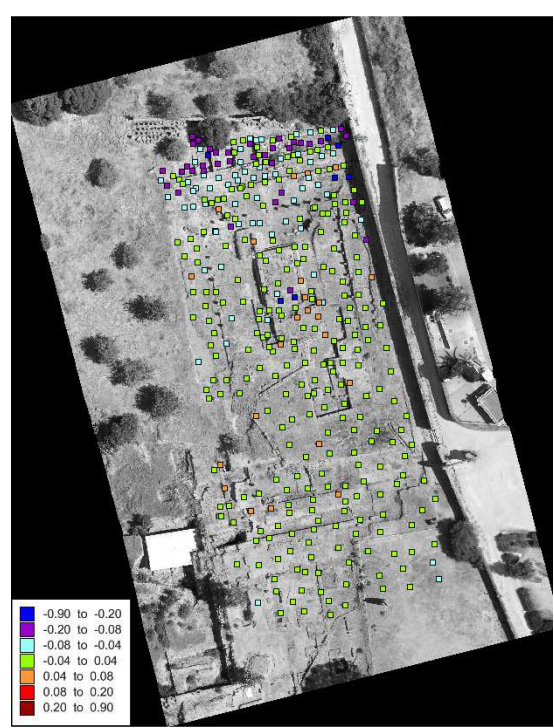

(c)

Figure 10. Graphic representation of the vertical differences (in $\mathrm{m}$ ) in 3D point cloud evaluation for the Temple of Isis: : East-West Block (a); North-South Block $(b)$; East-West + North-South Blocks $(c)$

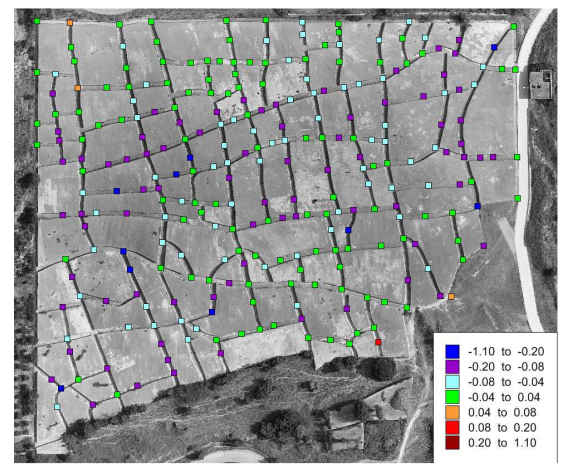

(a)

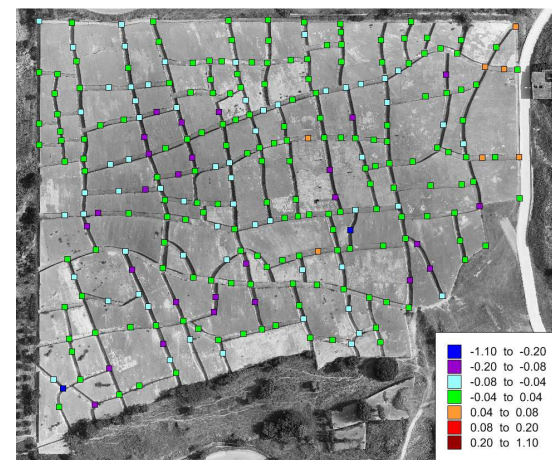

(b)

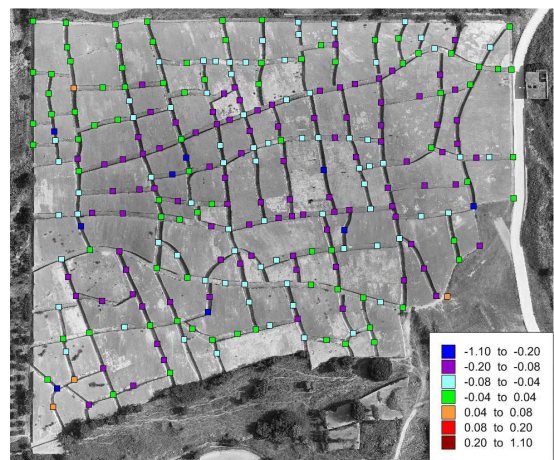

(c)

Figure 11. Graphic representation of the vertical differences (in $\mathrm{m}$ ) in 3D point cloud evaluation for the "Cretto of Gibellina": EastWest Block (a); North-South Block (b); East-West + North-South Blocks (c)

\section{REFERENCES}

\section{References from Journals:}

Chiabrando, F., Nex, F., Piatti, D., Rinaudo, F., 2011. UAV and RPV systems for photogrammetric surveys in archaeological areas: two tests in the Piedmont region (Italy). Journal of Archaeological Science, 38(3), pp. 697-710.

Eisenbeiss, H., Sauerbier, M., 2011. Investigation of UAV systems and flight modes for photogrammetric applications. The Photogrammetric Record, 26(136), pp. 400-421.

Lo Brutto, M., Borruso, A., D'Argenio, A., 2012. UAV Systems for photogrammetric data acquisition of archaeological sites. Journal of Heritage in the Digital Era, 1, Supplement 1, pp. 7-13.

Mancini, F.; Dubbini, M.; Gattelli, M.; Stecchi, F.; Fabbri, S.; Gabbianelli, G., 2013. Using Unmanned Aerial Vehicles (UAV) for High-Resolution Reconstruction of Topography: The Structure from Motion Approach on Coastal Environments. Remote Sensing, 2013, 5, pp. 6880-6898.

Rosnell, T.; ., Honkavaara, E., 2012. Point cloud generation from aerial image data acquired by a quadrocopter type micro unmanned aerial vehicle and a digital still camera. Sensors, 2012, 12, pp. 453-480.

Verhoeven, G., Doneus, M., Briese, C., Vermeulen, F., 2011. Mapping by matching: a computer vision-based approach to fast and accurate georeferencing of archaeological aerial photographs, Journal of Archaeological Science, 39(7), pp. 2060-2070.

\section{References from Other Literature:}

Haala N., Rothermel M., 2012. Dense multiple stereo matching of highly overlapping uav imagery. International Archives of the Photogrammetry, Remote Sensing and Spatial Information Sciences, Vol. XXXIX-B1, pp. 387-392.

Irschara, A., Kaufmann, V., Klopschitz, M., Bischof, H., Leberl, F., 2010. Towards fully automatic photogrammetric reconstruction using digital images taken from UAVs, International Archives of the Photogrammetry, Remote Sensing and Spatial Information Sciences, Vol. XXXVIII-7A, pp. 6570 .

Neitzel, F., Klonowski, J., 2011. Mobile 3D mapping with a low cost UAV system. International Archives of the Photogrammetry, Remote Sensing and Spatial Information Sciences, Vol. XXXVIII-1/C22, pp. 1-6. 
Nocerino, E., Menna, F., Remondino, F., Saleri, R., 2013. Accuracy and block deformation analysis in automatic UAV and Terrestrial photogrammetry - Lesson learnt. International Archives of the Photogrammetry, Remote Sensing and Spatial Information Sciences, Vol. II-5/W1, pp. 203-208.

Pueschel, H., Sauerbier, M., Eisenbeiss, H., 2008. A 3D model of Castle Landenberg $(\mathrm{CH})$ from combined photogrammetric processing of terrestrial and UAV-based images. International Archives of the Photogrammetry, Remote Sensing and Spatial Information Sciences, Vol. XXXVII-B6, pp. 93-98.

Remondino, F., Barazzetti, L., Nex, F., Scaioni, M., Sarazzi, D., 2011. UAV photogrammetry for mapping and 3D modellingcurrent status and future perspectives, International Archives of the Photogrammetry, Remote Sensing and Spatial Information Sciences, Vol. XXXVIII-1/C22, pp 25-31.

Seitz, C., Altenbach, H., 2011. Project archeye - the quadrocoprter as the archaeologist's eye, International Archives of the Photogrammetry, Remote Sensing and Spatial Information Sciences, Vol. XXXVIII-I/C22, pp. 297-302.

Gini R., Pagliari D., Passoni D., Pinto L., Sona G., Dosso P., 2014. UAV photogrammetry: block triangulation comparisons, International Archives of the Photogrammetry, Remote Sensing and Spatial Information Sciences, Vol. XL/W2, pp 157-162.

\section{ACKNOWLEDGEMENTS}

The authors would like to thank the "Landscape and Archaeological Park of the Valley of the Temples of Agrigento" institution for allowing access to the site and the Ticonzero Consortium and the Menci Software srl for the flights execution in the two study areas. 